Original Research Paper

\title{
Keberadaan Tempat Pembuangan Akhir Berdampak pada Kualitas Air
}

\author{
Abdonia W. Finmeta ${ }^{1 *}$, Nur Aini Bunyani ${ }^{1}$, Joritha Naisanu ${ }^{2}$ \\ ${ }^{1}$ Program Studi Biologi, Fakultas MIPA Universitas Persatuan Guru 1945 NTT, Indonesia \\ ${ }^{2}$ Program Studi Agroteknologi, Fakultas Pertanian Universitas Persatuan Guru 1945 NTT, Indonesia
}

\section{Riwayat artikel}

Received : 08 Oktober 2019

Revised : 12 Maret 2020

Accepted : 03 Juni 2020

Published : 05 Juni 2020

*Corresponding Author:

Abdonia W. Finmeta,

Universitas Persatuan Guru

1945 NTT,

Kota Kupang NTT ,Indonesia; Email:

finmeta.abdonia@gmail.com

\begin{abstract}
Abstrak: Tumpukan sampah dan lindi secara langsung dan tidak langsung dapat menganggu kesehatan lingkungan dan keseimbangan ekosistem perairan. Penelitian ini bertujuan untuk mengkaji kualitas fisik, kimia dan biologi air sumur pada berbagai jarak dari Tempat Pembuangan Akhir (TPA) kecamatanAlak serta dampaknya bagi kesehatan penduduk.Penelitian menggunakan metode stratified random sampling yaitu penentuan berdasarkan jarak $400 \mathrm{~m}-1200 \mathrm{~m}$ dari timbunan sampah dari lokasi pengambilan sampel air sumur. Hasil analisa sampel menentukan kualitas air dengan membandingkanbaku mutu Air. Analisis pengaruh jarak TPA terhadap kualitas air selanjutnya dihitung nilai determinasi $\left(\mathrm{r}^{2}\right)$ untukmenentukan hubungan jarakTPA terhadap kualitas air. Untuk menduga hubungan dilakukan dengan analisis regresi dan korelasi antara tumpukan sampah, air lindidan kualitas air tanah. Hasil Kualitas air sumur di kecamatan Alak berada pada kategori sesuai artinya sesuai dengan Permenkes No. 492/Menkes/Per/IV/2010 tanggal 19 April 2010. Variabel jarak keberadaan tempat pembuangan akhir berpengaruh terhadap kualitas air sumur. Parameter kualitas air yang diambil dari daerah pemukiman di kelurahanAlakpadajarak $800 \mathrm{~m}$ dan $1.200 \mathrm{~m}$ masih dalam batasaman dikonsumsi. Sedangkan pada jarak $400 \mathrm{~m}$ dibutuhkan perhatian pemerintah untuk pengelolaan TPA secarabaik agar tidak berdampak pada kesehatan masyarakat.
\end{abstract}

Kata kunci: Tempat Pembuangan Akhir, jarak TPA, kualitas air

Abstract: Piles of garbage and leachate directly and indirectly can disturb the health of the environment and the balance of the aquatic ecosystem. This study aims to assess the physical, chemical and biological quality of well water at various distances from the Final Disposal Landfill and its impact on the health of the population. The study uses a stratified random sampling method that is based on the distance of $400 \mathrm{~m}-1200 \mathrm{~m}$ from the landfill from the location of groundwater well sampling. The results of sample analysis determine water quality by comparing Water quality standards. Analysis of the effect of landfill distance on water quality then calculated determination value (r2) determines the relationship between landfill distance to water quality.To estimate the relationship is done by regression analysis and correlation between the garbage heap and leachate and ground water quality. Results The quality of well water in Alak sub-district is in the appropriate category according to the meaning of Permenkes No. 492 / Menkes / Per / IV / 2010 April 19, 2010. Variable distance of the existence of the final disposal site affects the quality of well water. Water quality parameters taken from residential areas in Alak village at a distance of $800 \mathrm{~m}$ and 1,200 m are still within the safe limits for consumption. Meanwhile, at a distance of $400 \mathrm{~m}$, government attention is needed to properly manage the landfill so it does not have an impact on public health.

Keywords: Landfills, Landfill distance, Water quality 


\section{Pendahuluan}

\section{Latar Belakang}

Pengelolaan sampah di kawasan sekitar TPA Alak dihadapkan pada berbagai permasalahan. Permasalahan tersebut meliputi tingginya laju timbunan sampah, kegiatan pembuangan akhir sampah yang mengganggu kesehatan masyarakat, estetika, dan kualitas lingkungan. Produksi sampah rumah tangga di Kota Kupang sudah mencapai 300-400 ton/hari (Dinas Kebersihan Kota Kupang, 2016). Sumber air di sekitar TPA yang tercemar oleh Tumpukan samah dan lindi secara langsung maupun tidak langsung dapat menganggu kesehatan lingkungan dan keseimbangan ekosistem perairan.

Air merupakan kebutuhan yang sangat vital bagi kehidupan dan sumber dasar untuk kelangsungan kehidupan di atas bumi. Keberadaan air mutlak diperlukan karena kehidupan di bumi tidak dapat berlangsung tanpa adanya air (Sanropie dkk, 1984). Sumber air untuk keperluan rumah tangga yang terbesar bagi rakyat Indonesia berasal dari sumur gali terlindung dengan prosentase 29,2 \%. (Riskesdas 2013) Bagi masyarakat Jawa Tengah air dari sumur gali terlindung masih menjadi sumber air utama bagi keperluan rumah tangga (BPS, 2017). Sedangkan 100\% Warga Dusun Sulurejo menggunakan air sumur gali untuk keperluan rumah tangga.

Jarak perumahan penduduk yang terdekat dengan TPA sekitar 200 meter. Keberadaan TPA Alak di sekitar pemukiman warga, terdapat rumah pemulung $35 \mathrm{KK}$. Kelurahan Alak adalah wilayah pengembangan pemukiman dan menjadi lokasi pendukung kawasan TPA Alak. Dipilihnya TPA Alak sebagai tempat penelitian dikarenakan beberapa permasalahan yang muncul diantaranya terdapat beberapa titik timbunan sampah yang cukup Tinggi. TPA Alak belum adanya fasilitas penyediaan air bersih dari PDAM.

Kebutuhan air sehari-hari, masyarakat di sekitar TPA menggunakan air tangki, air galon sebagai sumber air minum dan air sumur sebagai sumber keperluan mandi dan mencucia. Perusahaan Air Minum (PDAM) tidak mencukupi sehingga sebagian penduduk Kota Kupang masih menggunakan air tangki dan air sumur. Pelanggan PDAM Kota Kupang hanya mampu melayani pelanggan 5.200 pelanggan $/ 13,74 \%$ (BPS Kota Kupang, 2015), Agustus yaitu sebesar 4,112 m3/detik dengan nilai ketersediaan air tertinggi pada bulan Januari yaitu sebesar 204.629.856,800 m3 dan nilai ketersediaan air terendah terjadi pada bulan Agustus yaitu sebesar 10.657.759,680 m3 dengan ketersediaan air total selama satu tahun sebesar 1.271.005.476 m3.Oleh karena masih banyak rumah tangga yang menggunakan air bersih selain ledeng, maka dikhawatirkan air bersih yang digunakan tidak memenuhi persyaratan dilihat secara fisik, kimiawi, maupun bakteriologi ataupun air yang mengalami pencemaran (Pokja Sanitasi, 2011).

Hasil observasi di lapangan, masyarakat di sekitar TPA Alak menggunakan air isi ulang sebagai sumber utama untuk memenuhi kebutuhan makan dan minum, sedangkan untuk mandi dan mencuci menggunakan air tanah yang berasal dari sumur. Sumber air di sekitar TPA yang tercemar oleh lindi secara langsung maupun tidak langsung dapat menganggu kesehatan lingkungan dan keseimbangan ekosistem perairan tersebut. Dimana masyarakat di sekitar TPA masih memanfaatkan air tanah sebagai Berdasarkan hal tersebut, maka perlu dikaji pada bagaimana dampak timbunan sampah yaitu air lindi terhadap kualitas air tanah dan air permukaan di sekitar TPA Alak. Penelitian ini bertujuan untuk mengetahui kualitas air lindi pada berbagai jarak dari TPA Alak dan kualitas air lindi terhadap air tanah sesuai dengan baku mutu Air menurut Peraturan Menteri Permenkes No. 492/Menkes/Per/IV/2010 tanggal 19 April 2010.

\section{Tujuan}

Tujuan dari penelitian ini yakni untuk mengetahui pengaruh jarak keberadaan tempat pembuangan akhir terhadap kualitas air sumur di Kecamatan Alak Kota Kupang.

\section{Hipotesis}

Diduga terdapat pengaruh jarak keberadaan tempat pembuangan akhir terhadap kualitas air sumur di Kecamatan Alak Kota Kupang.

\section{Bahan dan Metode}

\section{Tempat dan waktu penelitian}

Penelitian dilakukan pada sumur penduduk di sekitar TPA Kecamatan Alak Kota Kupang. Kelurahan Alak adalah wilayah pemukiman yang terdiri dari 5 Rukun Tetangga dan menjadi lokasi pendukung kawasan TPA Alak. Berjarak sekitar $20 \mathrm{Km}$ dari pusat Kota Kupang. 


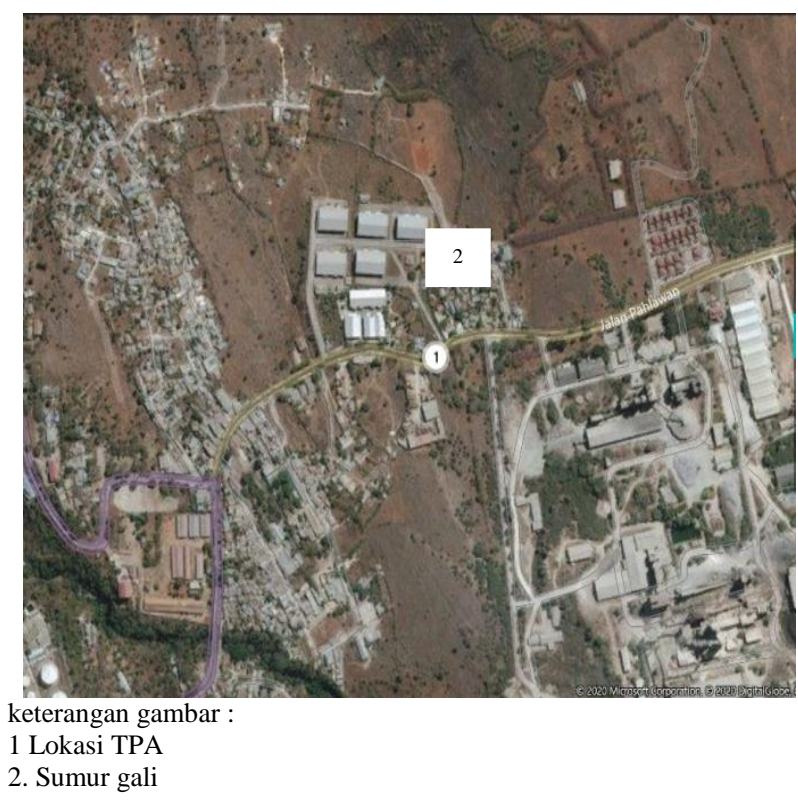

Gambar 1. TPA dan Sumur(digital globe, 2020)

Penelitian ini telah dilaksanakan selama dua bulan yaitu pada bulan April dan Desember 2019. Jumlah penduduk 5.392 Jiwa mempunyai unit Bangunan Permanen, 507 unit unit Bangunan Semi Permanen dan 69 Bangunan Darurat dan jumlah sumur 12 unit dengan jarak yang berbeda.

\section{Metode penentuan sampel}

Penentuan lokasi pengambilan sampel dilakukan dengan menggunakan metode statified random sampling yaitu penentuan berdasarkan jarak dari timbunan sampah dari lokasi pengambilan sampel air Sumur tanah, dan air permukaan (Penentuan sampel air baik sumur kemungkinan tercemar oleh air rembesan sampah serta berdasarkan letak sumber air sumur dari sumber timbunan. Penentuankulaitas air mengunakan standard Badan Standardisasi Nasional. 2004. SNI 06-6989.9-2004 Air dan air limbah.

\section{Variabel pengamatan}

Data parameter kimia, fisika, dan biologi pada sampel digunakan untuk menentukan kualitas air dengan cara membandingkan kualitas air berdasarkan nilai masing-masing parameter.

\section{Metode analisa data}

Untuk BIOSCIENTIAE. $2015 \quad 93$ menduga hubungan pengaruh jarak timbunan sampah terhadap kualitas air dilakukan dengan analisis regresi dan korelasi antara yaitu air lindi (sebagai variable bebas) dan Kualitas air permukaan dan air tanah (sebagai variable terikat). Untuk mengetahui hubungan antara dampak timbunan sampah dan air lindi (X) terhadap kualitas air (Y) digunakan analisis regresi linear (Harinaldi, 2005).

Ket.

$$
\mathrm{Yi}=\mathrm{a}+\mathrm{bXI}
$$

$\mathrm{Yi}=$ nilai yang diukur pada variable tidak bebas

$\mathrm{Xi}=$ nilai tertentu dari variable bebas

$\mathrm{a}=$ perpotongan garis regresi dengan sumbu y (intersep)

$\mathrm{b}=$ untuk mengukur kenaikan atau

penurunan y untuk setiap perubahan/ untuk mengukur besarnya pengaruh $\mathrm{x}$ terhadap $\mathrm{y}$ (koefisien regresi). Hasil analisis kemudian dibuat dalam bentuk grafik.

Untuk mengetahui kecenderungan pola dampak timbunan terhadap kualitas air digunakan analisis korelasi (Harinaldi, 2005). Uji Kualitas air sumur dibandingkan dengan baku mutu menurut Peraturan Menteri Kesehatan RI Permenkes No. 492/Menkes/Per/IV/2010.

Dengan ketentuan nilai $r$ tidak lebih dari harga $(-1 \leq \mathrm{r} \leq 1)$ apabila:

$r=-1$ artinya korelasi negatif sempurna

$\mathrm{r}=0$, artinya tidak ada korelasi

$\mathrm{r}=1$, arinya korelasi sempurna positif

Pengambilan sampel dilakukan pada bulan Juni 20119 dan Agustus 2019 dengan menggunakan waktu yang sama yaitu puluk $15.00 \mathrm{Wita}$

Sampel yang diperoleh di analisa di laboratorium Kesehatan propisi NTT untuk mengetahui karakteristik sampel meliputi: Fisika, Kimia, Biologi. Selanjutnya dianalisi pengaruh jarak TPA terhadap Kualitas air tahapan terakhir dihitung nilai determinasi $\left(\mathrm{r}^{2}\right)$ menentukan hubangan jarak dengan TPA terhadap kualitas air.

\section{Hasil dan Pembahasan}

\section{Kualitas Air}

Berdasarkan hasil uji laboratorium terhadap sampel air sumur gali milik warga seputar Tempat Pembuangan Akhir Alak Kecamatan Alak Kota Kupang pada beberapa parameter 
Tabel 1. Hasil Pemeriksaan Parameter

\begin{tabular}{|c|c|c|c|c|c|c|c|}
\hline \multirow{2}{*}{$\begin{array}{l}\text { Para- } \\
\text { meter } \\
\text { Fisika } \\
\text { Rasa }\end{array}$} & \multicolumn{2}{|c|}{ A1 (400 m) } & \multicolumn{2}{|c|}{ B1 $(800 \mathrm{~m})$} & \multicolumn{2}{|c|}{ C1(1200 m) } & \multirow{2}{*}{$\begin{array}{l}\text { Permenkes } \\
\text { No. } \\
\text { 492/Menke } \\
\text { s/Per } / \text { IV } / 20 \\
10 \\
\text { Tidak } \\
\text { berasa }\end{array}$} \\
\hline & $\begin{array}{l}\text { Tidak } \\
\text { berasa }\end{array}$ & sesuai & $\begin{array}{l}\text { Tidak } \\
\text { berasa }\end{array}$ & Sesuai & $\begin{array}{l}\text { Tidak } \\
\text { berasa }\end{array}$ & sesuai & \\
\hline Bau & $\begin{array}{l}\text { Tidak } \\
\text { berbau }\end{array}$ & Sesuai & $\begin{array}{l}\text { Tidak } \\
\text { berbau }\end{array}$ & Sesuai & $\begin{array}{l}\text { Tidak } \\
\text { berba } \\
\text { u }\end{array}$ & Sesuai & $\begin{array}{l}\text { Tidak } \\
\text { berbau }\end{array}$ \\
\hline Suhu & $28^{0} \mathrm{C}$ & $\begin{array}{l}\text { Tidak } \\
\text { sesuai }\end{array}$ & $28^{0} \mathrm{C}$ & $\begin{array}{l}\text { Tidak } \\
\text { sesuai }\end{array}$ & $28^{0} \mathrm{C}$ & $\begin{array}{l}\text { Tidak } \\
\text { sesuai }\end{array}$ & $\pm 3^{\circ} \mathrm{C}$ \\
\hline Warna & $\begin{array}{l}21 \\
\mathrm{TCU}\end{array}$ & $\begin{array}{l}\text { Tidak } \\
\text { sesuai }\end{array}$ & $43 \mathrm{TCU}$ & Sesuai & $\begin{array}{l}50 \\
\text { TCU }\end{array}$ & Sesuai & $50 \mathrm{TCU}$ \\
\hline $\begin{array}{l}\text { Daya } \\
\text { hantar } \\
\text { listrik }\end{array}$ & $562 \mu \mathrm{S}$ & & $628 \mu \mathrm{S}$ & & $\begin{array}{l}477 \\
\mu S\end{array}$ & & $\begin{array}{l}\text { Tidak } \\
\text { disyaratkan }\end{array}$ \\
\hline $\begin{array}{l}\text { Kekeruh } \\
\text { an } \\
\text { Kimia }\end{array}$ & $\begin{array}{l}0,03 \\
\text { NTU }\end{array}$ & $\begin{array}{l}\text { Tidak } \\
\text { sesuai }\end{array}$ & $\begin{array}{l}0,03 \\
\text { NTU }\end{array}$ & $\begin{array}{l}\text { Tidak } \\
\text { sesuai }\end{array}$ & $\begin{array}{l}0,03 \\
\text { NTU }\end{array}$ & $\begin{array}{l}\text { Tidak } \\
\text { sesuai }\end{array}$ & 5 NTU \\
\hline $\mathrm{pH}$ & 8,20 & Sesuai & 7,70 & sesuai & 8,19 & Sesuai & $6,5-8,5$ \\
\hline Bessi & $\begin{array}{l}0,00 \\
\mathbf{m g} / 1\end{array}$ & $\begin{array}{l}\text { Tidak } \\
\text { sesuai }\end{array}$ & $\begin{array}{l}0,00 \\
\mathrm{mg} / 1\end{array}$ & $\begin{array}{l}\text { Tidak } \\
\text { sesuai }\end{array}$ & $\begin{array}{l}0,02 \\
\mathrm{mg} / 1\end{array}$ & $\begin{array}{l}\text { Tidak } \\
\text { sesuai }\end{array}$ & $0,3 \mathrm{mg} / 1$ \\
\hline Mangan & $\begin{array}{l}0.026 \\
\mathrm{mg} / 1\end{array}$ & $\begin{array}{l}\text { Tidak } \\
\text { sesuai }\end{array}$ & $0.4 \mathrm{mg} / 1$ & sesuai & $\begin{array}{l}0.6 \\
\mathrm{mg} / 1\end{array}$ & Sesuai & $0.4 \mathrm{mg} / 1$ \\
\hline Sulfat & $10 \mathrm{mg} / 1$ & $\begin{array}{l}\text { Tidak } \\
\text { sesuai }\end{array}$ & $\begin{array}{l}210 \\
\mathrm{mg} / 1\end{array}$ & sesuai & $\begin{array}{l}280 \\
\mathrm{mg} / 1\end{array}$ & Sesuai & $250 \mathrm{mg} / 1$ \\
\hline TDS & $\begin{array}{l}408 \\
\mathrm{mg} / 1\end{array}$ & $\begin{array}{l}\text { Tidak } \\
\text { sesuai }\end{array}$ & $\begin{array}{l}441 \\
\mathrm{mg} / 1\end{array}$ & $\begin{array}{l}\text { Tidak } \\
\text { sesuai }\end{array}$ & $\begin{array}{l}337,1 \\
\mathrm{mg} / 1\end{array}$ & $\begin{array}{l}\text { Tidak } \\
\text { sesuai }\end{array}$ & $500 \mathrm{mg} / 1$ \\
\hline $\begin{array}{l}\text { TSS } \\
\text { Biologi }\end{array}$ & $4 \mathrm{mg} / 1$ & & $0 \mathrm{mg} / 1$ & & $0 \mathrm{mg} / 1$ & & $\begin{array}{l}\text { Tidak } \\
\text { disyaratkan }\end{array}$ \\
\hline$E-c o l y$ & 240 & $\begin{array}{l}\text { Tidak } \\
\text { sesuai }\end{array}$ & 0 & Sesuai & 0 & Sesuai & 0 \\
\hline $\begin{array}{l}\text { Total } \\
\text { coliform }\end{array}$ & 240 & $\begin{array}{l}\text { Tidak } \\
\text { sesuai }\end{array}$ & 0 & sesuai & 0 & sesuai & 0 \\
\hline
\end{tabular}

Keterangan : Hasil pemeriksaan Parameter fisika, kimia dan biologi dibandingkan dengan Peraturan Menteri Kesehatan Republik Indonesia No. 492/Menkes/Per/IV/2010 tentang Persyaratan Kualitas Air Minum.

Tabel diatas menunjukan ditinjau dari parameter fisika, jarak air sumur gali dan TPA $400 \mathrm{~m}, 800 \mathrm{~m}$ dan $1200 \mathrm{~m}$ memiliki rasa dan bau yang sesuai, sedangkan suhu tidak sesuai. selanjutnya warna untuk jarak $400 \mathrm{~m}$ tidak sesuai namun jarak $800 \mathrm{~m}$ dan $1200 \mathrm{~m}$ sesuai.

Untuk parameter kimia, jarak air sumur gali dan TPA $400 \mathrm{~m}, 800 \mathrm{~m}$ dan $1200 \mathrm{~m}$ memiliki $\mathrm{pH}$ yang sesuai sedangkan kandungan besi tidak sesuai. Selanjutnya kandungan mangan dan sulfat sesuai untuk jarak $800 \mathrm{~m}$ dan $1200 \mathrm{~m}$ sedangkan $400 \mathrm{~m}$ tidak sesuai.

Parameter Biologi, jarak air sumur gali dan TPA $800 \mathrm{~m}$ dan $1200 \mathrm{~m}$ memiliki e-coly dan total coliform yang sesuai sedangkan jarak $400 \mathrm{~m}$ tidak sesuai untuk semua parameter biologi yang uji.

Berdasarkan persyaratan air minum tersebut untuk parameter rasa yang diperbolehkan tidak berasa. Hasil uji laboratorium air sumur gali milik warga menunjukkan sampel air yang diuji tidak berasa. Air sumur galih dengan jarak dari TPA 400m - $1200 \mathrm{~m}$. untuk parameter rasa memenuhi persyaratan kualitas air minum, hal ini disebabkan topografi kota kupang curam $90 \%$, sehingga parameter rasa sesuai dengan kriteria air minum. Berdasarkan persyaratan air minum tersebut untuk parameter bau yang diperbolehkan tidak berbau. Hasil uji 
laboratorium air sumur gali milik warga menunjukkan sampel air yang diuji tidak berbau. Air sumur galih dengan jarak dari TPA 400m - $1200 \mathrm{~m}$. untuk parameter bau memenuhi persyaratan kualitas air minum sesuai Peraturan Menteri Kesehatan Republik Indonesia No. 492/Menkes/Per/IV/2010 tentang Persyaratan Kualitas Air Minum. Hasil penelitian ini tidak sesuai dengan, 1 penelitian menunjukan parameter Wama, bau, TSS, BOD dan COD dari Air Lindi melampaui baku mutu (Erni Mahluddin Yatim,* Mukhlis, 2013), hal ini bisa disebabkan karena kedalaman sumur galih rata-rara 30-40 meter sehingga tidak mencemari.

Hasil uji laboratorium air sumur galih milik warga menunjukkan sampel air yang diuji tidak berbau. Air sumur galih dengan jarak dari TPA 400m - 1200 m. untuk parameter bau memenuhi persyaratan kualitas air minum sesuai Peraturan Menteri Kesehatan Republik Indonesia No. 492/Menkes/Per/IV/2010 tentang Persyaratan Kualitas Air Minum.

Hasil uji laboratorium air sumur gali milik warga menunjukkan sampel air yang diuji dengan kekeruhan 0,03 NTU. Air sumur galih dengan jarak dari TPA 400m - 1200 m. untuk parameter kekeruhan masih sesuai kualitas air minum sesuai Peraturan Menteri Kesehatan Republik Indonesia No. 492/Menkes/Per/IV/2010 tentang Persyaratan Kualitas Air Minum, kriteria yang disyaratkan adalah kekeruhan 5 NTU.

Hasil uji laboratorium air sumur gali milik warga menunjukkan sampel air yang diuji dengan pH8,19-8,20. Air sumur galih dengan jarak dari TPA 400m - 1200 m. untuk parameter $\mathrm{pH}$ sesuai kualitas air minum sesuai Peraturan Menteri Kesehatan Republik Indonesia No. 492/Menkes/Per/IV/2010 tentang Persyaratan Kualitas Air Minum kriteria yang disyaratkan adalah suhu $\mathrm{pH} 8,5$.

Hasil penelitian ini sesuai dengan penelitian Hadid Amirul Arifin 2018 yang menyatakan bahwa jarak tidak berpengaruh terhadap parameter kekeruhan, bau, rasa, $\mathrm{pH}$ dan Nitrat.

Hasil uji laboratorium air sumur gali milik warga menunjukkan sampel air yang diuji dengan suhu $28^{\circ} \mathrm{C}$. Air sumur galih dengan jarak dari TPA 400m - 1200 m. untuk parameter suhu tidak sesuai kualitas air minum sesuai Peraturan Menteri Kesehatan Republik Indonesia No. 492/Menkes/Per/IV/2010 tentang Persyaratan Kualitas Air Minum kriteria yang disyaratkan adalah suhu $\pm 3^{\circ} \mathrm{C}$

Hasil uji laboratorium air sumur gali milik warga menunjukkan sampel air yang diuji dengan Besi 0,00$0,02 \mathrm{mg} / \mathrm{l}$. Air sumur galih dengan jarak dari TPA 400m 1200 m. untuk parameter pH sesuai kualitas air minum sesuai Peraturan Menteri Kesehatan Republik Indonesia No. 492/Menkes/Per/IV/2010 tentang Persyaratan Kualitas Air Minum kriteria yang disyaratkan adalah Besi $0,3 \mathrm{mg} / \mathrm{l}$.

Hasil uji laboratorium air sumur gali milik warga menunjukkan sampel air yang diuji dengan Mangan
0,026- 0,4 mg/l sesuai dengan persyaratan. Air sumur galih dengan jarak dari TPA $400 \mathrm{~m}$ dan $800 \mathrm{~m}$ sedangkan jarak $1200 \mathrm{~m}$ hasil uji 0,6 mg/l tidak sesuai dengan persyaratan. untuk parameter $\mathrm{pH}$ sesuai kualitas air minum sesuai Peraturan Menteri Kesehatan Republik Indonesia No. 492/Menkes/Per/IV/2010 tentang Persyaratan Kualitas Air Minum kriteria yang disyaratkan adalah Mangan 0,4 mg/l.

Hasil uji laboratorium air sumur gali milik warga menunjukkan sampel air yang diuji Sulfat 10-280 mg/l untuk jarak 400m sedangkan $210 \mathrm{mg} / \mathrm{l}$. Air sumur galih sumur galih ini kadungan mangan masih sesuai dengan persyaratan sedangkan jarak $1200 \mathrm{~m}$ hasil uji $280 \mathrm{mg} / \mathrm{l}$ tidak sesuai dengan persyaratan kualitas air minum sesuai Peraturan Menteri Kesehatan Republik Indonesia No. 492/Menkes/Per/IV/2010 tentang Persyaratan Kualitas Air Minum kriteria yang disyaratkan adalah sulfat 250 $\mathrm{mg} / \mathrm{l}$.

Hasil uji laboratorium air sumur galih milik warga menunjukkan sampel air yang diuji Sulfat 10-280 mg/l untuk jarak 400m sedangkan $210 \mathrm{mg} / \mathrm{l}$. Air sumur galih sumur galih ini kadungan mangan masih sesuai dengan persyaratan sedangkan jarak $1200 \mathrm{~m}$ hasil uji $280 \mathrm{mg} / \mathrm{l}$ tidak sesuai dengan persyaratan kualitas air minum sesuai Peraturan Menteri Kesehatan Republik Indonesia No. 492/Menkes/Per/IV/2010 tentang Persyaratan Kualitas Air Minum kriteria yang disyaratkan adalah sulfat 250 $\mathrm{mg} / \mathrm{l}$.

Untuk TSS tidak disyaratkan sesuai Peraturan Menteri Kesehatan Republik Indonesia No. 492/Menkes/Per/IV/2010. Hasil uji TDS berkisar, 337,1 $441 \mathrm{mg} / \mathrm{l}$ menujukkan kandungan TDS sesuai dengan Peraturan Menteri Kesehatan Republik Indonesia No. 492/Menkes/Per/IV/2010 tentang Persyaratan Kualitas Air Minum kriteria yang disyaratkan adalah sulfat 500 $\mathrm{mg} / \mathrm{l}$.

Hasil uiji e.Coly di sumur galih dengan jarak 400m yaitu 240 ini tidak sesuai Peraturan Menteri Kesehatan Republik Indonesia No. 492/Menkes/Per/IV/2010 tentang Persyaratan Kualitas Air Minum kriteria yang disyaratkan adalah e.Coly 0 .

Hasil uiji total coliform di sumur galih dengan jarak 400m yaitu 240 ini tidak sesuai sedangkan jarak 800 m yaitu 80 sedangkan $1200 \mathrm{~m}$ adalah 21 dengan jarak dari tumpukan sampah galih 400,800,1200 m total coliform tidak sesuai Peraturan Menteri Kesehatan Republik Indonesia No. 492/Menkes/Per/IV/2010 tentang Persyaratan Kualitas Air Minum kriteria total coliform yang disyaratkan adalah 0 .

Berdasarkan hasil uji fisika, kimiadanbiologi menunjukan bahwa semakin dekat jarak (400 m) nilai parameternya menjadi tidak sesuai permendiknas 492/Menkes/Per/IV/2010 menjadi tidak sesuai. Hasil ini sesuai dengan hasil penelitian Aryani (2018) jarak 247 belum memenuhi standard baku air bersih. 


\section{Keberadaan Tempat Pembuangan Akhir terhadap Kualitas air}

Kualitas

sumur

di

Kecamatan Alak Kota Kupang dipengaruhi oleh Jarak keberadaan tempat pembuangan akhir. Hasil analisis dapat dilihat pada Tabel 2. Model regresi berdasarkan hasil analisis dapat dilihat pada fungsi berikut :

$$
\mathrm{K}_{\text {ualitas air }}=0,190+0,001 \mathrm{~J}_{\text {arak }}
$$

Tabel 2. Hasil Analisis Regresi

\begin{tabular}{|ll|cc|c|c|}
\hline N & Variabel & $\begin{array}{c}\text { Coefficient } \\
\text { s }\end{array}$ & $\begin{array}{c}\text { Std. } \\
\text { Error }\end{array}$ & t-Statistic & Sig. \\
\hline 1 & C(bo) & 0,190 & 0,026 & 7,224 & .000 \\
\hline 2 & Jarak & 0,001 & 0,000 & 15,376 & .000 \\
\hline 3 & R-squared & & .971 & \\
4 & Adjusted R-squared & & .967 & \\
5 & Std. Error of the Estimate & & 0,03720 & \\
6 & F-statistic & & 236,410 & \\
7 & Prob(F-statistic) & & $.000^{\mathrm{b}}$ & \\
\hline
\end{tabular}

Sumber : Analisis Data Primer, 2019

Hasil Analisis menunjukan bahwa nilai $\mathrm{b}_{0}$ bernilai positif 0,190 hal ini berarti bahwa pada saat Jarak keberadaan tempat pembuangan akhir 0 meter maka kualitas air sumur sebesar 0,190.

Nilai koefisien regresi $b_{1}$ sebesar positif 0,001 hal ini berarti bahwa Jarak keberadaan tempat pembuangan akhir meningkat sebesar $1 \mathrm{~m}$ maka kualitas air akan meningkat sebesar 0,001 . Hal ini berarti bahwa semakin jauh Jarak keberadaan tempat pembuangan akhir maka kualitas air akan meningkat. Hasil penelitian ini sesuai dengan penelitian Grecyet al. (2015) yang menjelaskan bahwa terdapat hubungan yang sangat kuat antara pengaruh arak timbunan sampah terhadap kualitas air untuk parameter total coliform.

Nilai $\mathrm{F}$ hitung sebesar 236,410 lebih besar dari nilai $\mathrm{F}$ tabel pada tingkat kepercayaan $99 \%$. Hal ini berarti bahwa kualitas air sumur dipengaruhi oleh Jarak keberadaan tempat pembuangan akhir.

Besarnya keragaman variabel kualitas air dapat dijelaskan oleh variabel Jarak keberadaan tempat pembuangan akhir. Hasil analisis menunjukkan oleh besarnya nilai koefisien determinasi $\left(\mathrm{R}^{2}\right)$. Nilai sebesar 0,971 yang berarti bahwa 97,1\% keragaman variabel Kualitas air sumur yang dimasukkan dalam model dapat dijelaskan oleh keragaman variabel Jarak keberadaan tempat pembuangan akhir. Sedangkan 2,1\% diterangkan oleh variabel lain diluar model. Hasil analisis juga menunjukan bahwa hubungan kualitas air dan Jarak keberadaan tempat pembuangan akhir bersifat korelasi positif $(r=0,986)$.
Untuk mengetahui variabel independen yang nyata pengaruhnya terhadap kulitas air digunakan uji t. Hasil analisis dengan menggunakan uji t dua arah menunjukkan bahwa variable Jarak keberadaan tempat pembuangan akhir berpengaruh sangat nyata terhadap kualitas air sumur pada tingkat kepercayaan $99 \%$. Hal ini disebabkan karena semakin jauh Jarak keberadaan tempat pembuangan akhir akan semakin mengurangi tingkat peresapan air sehingga kualitas air semakin meningkat.

Berdasarkan hasil penelitian, jarak pembuangan akhir yang terdapat di Kecamatan Alak Kota kupang bervariasi antara $200 \mathrm{~m}$ sampai $800 \mathrm{~m}$. Berikut ini ditampilkan Gambar Jarak Peembuangan Akhir dari sampah.

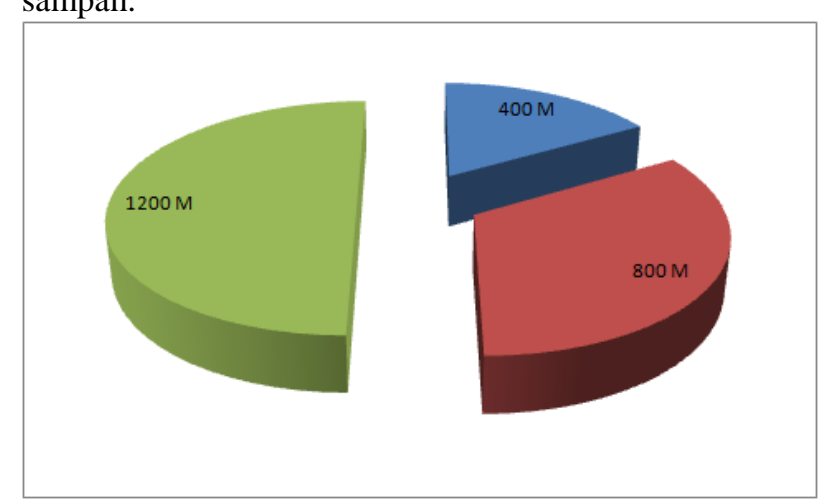

Sumber : data primer diolah

Gambar di atas menjelaskan bahwa jarak pembuangan akhir bervariasi tergantung dari kepadatan penduduk di Kecamatan Alak yang rata-rata berkisar antara 400-1200M. Semakindekatjarak TPA dan sumur maka akan berdampak pada pencemaran air sehingga menjadi tidak layak untuk dikonsumsi bagi masyarakat sekitar.

\section{Kesimpulan}

Kualitas air sumur di kecamatan Alak berada pada kategori sesuai artinya sesuai dengan Permenkes No. 492/Menkes/Per/IV/2010 tanggal 19 April 2010. Untuk parameter e.Coly dengan jarak 400 meter tidak sesuai sedangkan semua jarak pengamatan total coliform tidak sesuai dengan yang disyaratkan. Variabel jarak keberadaan tempat pembuangan akhir berpengaruh terhadap kualitas air sumur.Parameter kualitas air yang diambil dari daerah pemukiman di kelurahan alak pada jarak $800 \mathrm{~m}$ dan $1.200 \mathrm{~m}$ masih dalam batas aman dikonsumsi. Sedangkan pada jarak $400 \mathrm{~m}$ dibutuhkan perhatian pemerintah untuk pengelolaan TPA secara baik agar tidak berdampak pada kesehatan masyarakat. 


\section{Ucapan Terima Kasih}

Puji syukur kepada Tuhan Yang Maha Esa karena Kuasa dan RahmatNya sehingga Artikel ini dapat terselesaikan dengan baik. Selama kegiatan ini berlangsung 6 bulan tim pelaksana telah menerima bantuan moril maupun materil dari berbagai pihak. Oleh karena itu pada kesempatan ini kami mengucapkan terima kasih kepada: Direktorat Penelitian dan Pengabdian Kepada Masyarakat, DRPM Jakarta atas bantuan dana sehingga kegiatan ini dapat terlaksana dengan baik, LL2DIKTI Wilayah VIII Bali Nusra Di Bali, Rektor Universitas Persatuan Guru 1945 NTT yang telah membantu baik moril maupun materil terlaksananya kegiatan ini, Dekan FMIPA Universitas Persatuan Guru 1945 NTT yang telah memberikan bantuan moril hingga terlaksananya kegiatan ini dan Kepala Laboratorium Dinas Kesehatan Propinsi NTT

\section{Daftar Pustaka}

Arianto, Febbry (2011). Kelayakan Air Sumur sebagai Sumber Air Bersih di Lereng Sebelah Utara TPA Piyungan. Skripsi. Yogyakarta: Universitas Negeri Yogyakarta. https://ejournal.unair.ac.id/JKL/article/view/9381

Arifin, H.A. (2018). Pengaruh Jarak Sumur Dari Tempat Pembuangan Akhir Sampah Putri Cempo Terhadap Kualitas Air Sumur Warga Sulurejo. https://core.ac.uk/download/pdf/154927242.pdf

Arsyad, S. (1989). Konsevasi Tanah dan Air. Penerbit Instutut Pertanian Bogor Press. Bogor. https://docplayer.info/49380238-Arsyad-skonservasi-tanah-dan-air-penerbit-ipb-ipb-pressbogor.html

Badan Standardisasi Nasional. 2004. SNI 06-6989.9-2004 Air dan air limbah. diakses tanggal 28 Desember 2017. https://bsn.go.id/

Badan Pusat Statistik (2017). Presentase Rumah Tangga Menurut Provinsi dan Sumber Air Minum 2000-2015. Diakses: 18 November 2017. https://www.bps.go.id/linkTabelStatis/view/id/13 61.

Dwiriatanti, D. (2005). Pengolahan Lindi Dengan Biji kelor Moringa Oleifera. http://ejournal.uin malang.ac.id/index.php

Dinas Kebersihan Kota Kupang (2016). Detail Engineering Design Persampahan Kota Kupang: Dinas Kebersihan Kota. http://kupangkota.go.id/v4/index.php/profil/skpd/ dinas/188-dinas-kebersihan-dan-pertanaman

Daryanto (1995). Ekologi dan sumber daya alam. Bandung Tarsito.

Effendi, H. (2003). Telaah Kualitas air bagi Pengolahan Sumber Daya dan Lingkungan Perairan, Yogyakarta: Percetakan Kanisius.

Firta Desi Nur Aryani (2015). Kualitas Air Tanah Di Sekitar Lokasi Tempat Pembuangan Akhir Untuk Pemenuhan Kebutuhan Air Bersih (Studi Kasus: Tpa Banyuroto Dan Tpa Piyungan) Ground Water Quality Around Landfill For The Fulfillment Of Clean Water Needs (Study Case: Banyuroto Landfill And Piyungan

Landfill Program Studi Pendidikan Geografi, Fakultas Ilmu Sosial, Universitas Negeri Yogyakarta.

https://www.scribd.com/document/403234928/10 195-22466-1-SM-air-tanah

Fajarini, S. (2014). Analisis Kualitas Air Tanah Masyarakat di Sekitar Tempat Pembuangan Akhir (TPA) Sampah Kelurahan Sumurbatu Bantar Gebang, Bekasi Tahun 2013. [Skripsi Ilmiah]. Universitas Islam Negeri Syarif Hidayatullah Jakarta. https://id.123dok.com/document/dzxnxnnqanalisis-kualitas-air-tanah-masyarakat-di-sekitartempat

Grecy Mulya Sari, Munawar \& A. Napoleon (2015). Kualitas Air di Sekitar Eks Tempat Pembuangan Akhir Karya Jaya Palembang, Bioscientiae, 12 (1) : 90 - 101 http://fmipa.unlam.ac.id

Hammer, Mark, J \& Hammer, Mark J. Jr. (1996). Water and Wastewater Technology, Third Edition, Prentice Hall International Edition

Harinaldi (2005). Prinsip-prinsipStatistik untuk Teknik dan Sains. Jakarta : Erlangga. ISBN: 978- 979015-989-1

Haslinda, Tuti (1998). Hubungan SanitariLandfill dengan Kualitas Air Tanah. Depok Universitas Indonesia. https://sil.ui.ac.id/alumni-s2/

Hendra Andiananta Pradana, Sri Wahyuningsih, Elida Novita, Aisyah Humayro \& Bambang Herry Purnomo (2019). Identifikasi Kualitas Air dan Beban Pencemaran Sungai Bedadung di Intake Instalasi Pengolahan Air PDAM Kabupaten 
Jember 1 Magister Pengelolaan Sumber Daya Air Jurnal Kesehatan Lingkungan Indonesia 18 (2), 2019, 135 - 143 DOI : 10.14710/jkli.18.2.135-143 Pertanian. file:///C:/Users/hp/Downloads/2495772884-2-PB\%20(2).pdf

Iriani, L. G. (2014). Analisis Kualitas Air Tanah Bebas Di Sekitar TPA Banyuroto Desa Banyuroto Kecamatan Nanggulan Kabupaten Kulon Progo Yogyakarta. [Naskah Publikasi]. Universitas Muhammadiyah Surakarta. https://www.scribd.com/document/403234928/10 195-22466-1-SM-air-tanah

Kementerian Kesehatan RI. (2013). Riset Kesehatan Dasar 2013. Jakarta: Kementerian Kesehatan RI. https://doczz.net/doc/110324/hasil-riskesdas2013---kementerian-kesehatan

Indah.A.Y., Hilda Zulkifli \& M. Faisal (2006). Pengaruh Lindi TPA Sampah Batu Putih Kabupaten OKU Terhadap Kualitas air di sekitar TPA. Jurnal Pengelolaan Lingkungan. 4(2) : 37-46. https://www.jurnal-doc.com/jurnal/jurnalpengelolaan-lingkungan

Pokja Sanitasi Kota Palembang (2011). Buku Putih Sanitasi Kota Palembang. Palembang: Bappeda Prihastini, Lilis. 2011. Dampak Tempat Pembuangan Akhir (TPA) Sampah Winongo terhadap Kualitas Lingkungan Hidup. Jurnal Penelitian. http://www.ampl.or.id/digilib/read/12draft-stategi-sanitasi-kota-palembang/3199

Peraturan Menteri Kesehatan (1990). Lampiran Peraturan Menteri Kesehatan No.416/PER/X/1990 tentang Syarat-syarat dan Pengawasan Kualitas Air. Jakarta: Departemen Kesehatan RI. https://www.slideshare.net/infosanitasi/permenkes-416-90-syaratsyarat-dan-pengawasankualitas-air

Prihastini, Lilis (2011). Dampak Tempat Pembuangan Akhir (TPA) Sampah Winongo terhadap Kualitas Lingkungan Hidup. Jurnal PenelitianKesehatan Suara Forikes. 2 (1): 6-15.

Putra, I Ketut (2012). Identifikasi Arah Rembesan dan Letak Akumulasi Lindi dengan Metode Geolistrik Resistivitas Konfigurasi WennerSchumberger di TPA Temesi Kabupaten Gianyar. TESIS. Denpasar: Universitas Udayana. Kota Kupang Dalam Angka , (2017) BPS Kota
Kupang. SNI 06-2412-1991. Metode Pengambilan Contoh Air. (diakses tanggal 19 Maret 2014).

Wardhana, Irwan Wisnu (2007). Rencana Pengembangan Teknik Operasional Sistem Pengelolaan Sampah Kota Juwana . jurnal Presipitasi. 3(2): 102-110

Veybi Djoharama, Etty Rianib, Mohamad Yani. Quality Analysis and Pollution Load Capacity of Pesanggrahan River, Province of DKI Jakarta. Jurnal Pengelolaan Sumberdaya Alam dan Lingkungan, 8 (1) (April 2018): 127-133 doi: 10.29244/jpsl.8.1.127-133 https://media.neliti.com/media/publications/2293 15-analisis-kualitas-air-dan-daya-tampung-b9ef7ee99.pdf 